\title{
Research
}

\section{Domestic abuse and women's health: the challenge for primary care}

Sue Peckover, Department of Community, Ageing, Rehabilitation, Education and Research, School of Nursing and Midwifery, University of Sheffield, Sheffield, UK

\begin{abstract}
The recent interest in the issue of domestic abuse has highlighted its adverse impact upon womens' health, together with the need to improve health care responses. Whilst this has implications across health services, the raised awareness of domestic abuse as a health care issue is particularly important for primary care. This is not only due to the nature of primary care contact with women experiencing domestic abuse, but also because the current modernization of primary care, which includes organizational change, enhanced public health, increased partnership working and new forms of service delivery, provides an ideal opportunity to improve the services which are delivered to women experiencing domestic abuse. There are, however, a number of challenges to achieving real changes in practice. These include the complexities of domestic abuse which will always be competing with other clinical priorities, as well as the complexities of primary care which crosses a number of organizational and professional boundaries. Moreover, whilst the recognition that domestic abuse is a health care issue is to be welcomed, concerns relating to the medicalization and professionalization of what is essentially a social problem are highlighted.
\end{abstract}

Key words: domestic violence; primary care; public health; women's health

\section{Introduction}

The arrival of domestic abuse upon the UK health care agenda marks the merging of a number of key interests and developments across the academic and professional health and social sciences arena. These include a recognition that experiencing domestic abuse has an adverse impact upon womens' health, and that the responses of health care professionals need to be vastly improved. This has been associated with the development of resources for health care professionals, including information, training and guidelines about the implementation of good practice (for example, Bewley et al., 1997; British Medical Association,

Address for correspondence: Sue Peckover, Department of Community, Ageing, Rehabilitation, Education and Research, School of Nursing and Midwifery, University of Sheffield, Samuel Fox House, Northern General Hospital, Herries Road, Sheffield S5 7AU, UK. Email: S.Peckover@ sheffield.ac.uk
1998; Community Practitioners and Health Visitors Association, 1998; Department of Health, 2000; Heath, 1992; Home Office, 1999; Peckover, 2000; Royal College of Midwives, 1997). This interest has emerged at a time of a revitalized public health strategy which has re-emphasized the importance of social structural issues as key determinants of health (Department of Health, 1997a). However, the relationship between domestic abuse and health is not a new issue. For many years voluntary sector organizations, such as Women's Aid who provide support to women experiencing domestic abuse, have highlighted its health and social consequences (Dobash and Dobash, 1979; Kelly, 1988; Mama, 1989; Pahl, 1995; Stark and Flitcraft, 1996; Stanko et al., 1998), while outside this country, particularly in the USA, a long-established interest and expertise within the health sector about domestic abuse can be easily identified (see for example, Sampselle, 1992; Stark and Flitcraft, 1996). 
Primary care is often the first point of contact for women seeking help, as well as the service that will provide care for many of the long-term health and social problems associated with domestic abuse. Meeting the needs of women experiencing domestic abuse, however, represents a particular challenge for primary care services, largely due to the complexities involved. The challenges are particularly salient given the current modernization of primary care, which includes organizational change, a strengthening of public health perspectives, and an increased emphasis upon both interagency working and public participation. While this provides an ideal opportunity to develop more appropriate and effective primary care services for women experiencing domestic abuse, there are difficulties in achieving real changes in practice. Domestic abuse is a complex issue, and will always be competing with other more established health care issues, such as coronary heart disease. Moreover, beyond the policy and practice agenda, there has been little critical discussion about the medicalization and professionalization of what is essentially a social problem. This paper aims to provide an overview of these issues commencing with a discussion of the impact of domestic abuse upon women's health, and the policy and practice implications this has for primary care services.

\section{Domestic abuse: definitions and extent}

Domestic abuse is becoming a widely used term to describe a range of abuses, largely experienced by women, from their partners or former partners. This includes emotional, sexual and financial abuse, as well as physical abuse, intimidation and threats. While it is acknowledged that domestic abuse can be experienced by men from their female partners, and that it also occurs in same sex relationships, the overwhelming majority of domestic abuse is perpetrated by men against women (Kelly, 1988; McWilliams and McKiernan, 1993; Mirlees-Black and Byron, 1999; Mooney, 1993). While there are difficulties in determining the exact extent of domestic abuse, current evidence suggests that one in four women have suffered domestic abuse at some time in their adult lives, and one in nine women have experienced physical abuse during the previous 12 months (Home Office, 1999; McGibbon et al., 1989; Mooney,
1993; Stanko et al., 1998). Domestic abuse is experienced by women from all walks of life, regardless of race, class, age and (dis)ability. This makes it a universally relevant issue, and not just a problem for primary care services delivered in communities marked by social exclusion.

\section{The impact of domestic abuse upon women's health}

For many years the prevailing silence about domestic abuse meant that there was little awareness of the issue and its health consequences. This silence involved a reluctance on the part of health care workers to directly ask about experiences of domestic abuse, as well as women's reluctance to reveal or discuss their experiences of domestic abuse to health care workers due to embarrassment, fear and concern about losing custody of their children (Kelly and Radford, 1991; Kelly, 1994; McWilliams and McKiernan, 1993; Pahl, 1985). However, the issue of domestic abuse is now beginning to be more widely recognized and there is growing evidence that it is a major cause of illness, injury and death.

Much of the work establishing the impact of domestic abuse upon women's health has been undertaken outside this country, notably in the USA (see for example, Abbott, 1997; Council of Scientific Affairs, 1992; Haber, 1985; Jaffe et al., 1986; Muelleman et al., 1996; Plichta, 1992; Stark et al., 1979), although UK feminist work exploring women's experiences has consistently highlighted their poorer health status (see for example, Dobash and Dobash, 1979; Kelly, 1988; Mooney, 1993; Pahl, 1985; Stanko et al., 1998). The professional and academic community within the UK has begun to establish health-related evidence for women experiencing domestic abuse (see for example, Bewley et al., 1997; British Medical Association, 1998; Williamson, 2000). Although the health economic implications have not been fully evaluated, a recent study suggested that domestic abuse represented an annual cost to the health service of $£ 189$ million in Greater London alone (Stanko et al., 1998).

Experiencing domestic abuse compromises womens' health status in a number of ways. The physical injuries they sustain are often multiple and can include bruises, cuts, broken bones, burns and 
wounds. As well as the immediate problems associated with these injuries, there is often longer-term damage, such as scars, damage to joints, backache, loss of hearing and vision, long-term chronic pain and physical disabilities (see for example, Abbott, 1997; Council of Scientific Affairs, 1992; Haber, 1985; Muelleman et al., 1996; Plichta, 1992). Domestic abuse injuries are often fatal; figures suggest that on average two women per week are killed in England and Wales by their partners or ex-partners (Mirlees-Black and Byron, 1999).

Domestic abuse has an adverse impact upon womens' mental health and is associated with higher rates of depression, anxiety, stress-related illness, self-harm and suicide (Abrahams, 1994; Andrews and Brown, 1988; Hilberman and Munson, 1977; Jaffe et al., 1986; Stark et al., 1979). For example, in an interview-based study undertaken with 286 working class mothers living in North London, Andrews and Brown (1988) found that women who had ever been in a violent relationship were twice as likely to be depressed and had lower self-esteem, than those women in the study who did not report a history of domestic abuse. Similarly Jaffe et al. (1986) found that 56 women who had escaped domestic abuse and were living in women's shelters had significantly more somatic complaints, a higher level of anxiety and reported more symptoms of depression, compared with a convenience matched sample of 89 women not reporting domestic abuse. In an analysis of the case records of 481 women attending for emergency care at a US hospital, Stark et al. (1979) found that one in four 'battered women' had attempted suicide at least once, establishing that self-abuse, attempted suicide and deteriorating mental health follow on from the experience of abuse, and are not preconditions for it.

Domestic abuse often commences or escalates during pregnancy and continues during the postnatal period making it a key determinant of the health and well-being of mothers and their babies (Gielen et al., 1994; Helton et al., 1987; Helton and Snodgrass, 1987; McFarlane et al., 1992). The extent of domestic abuse during pregnancy is difficult to determine, but as Mezey and Bewley (1997) point out '.. it appears to be a more frequent occurrence than other recognized obstetric complications such as pre-eclampsia, placenta praevia, twins or gestational diabetes'
(Mezey and Bewley, 1997: 528). Experiencing domestic abuse during pregnancy is associated with physical injuries, poorer overall maternal health and maternal death (Department of Health, 1998b), while poorer obstetric outcomes include miscarriages, preterm labour and low birth weight infants (Andrews and Brown, 1988; Bullock and McFarlane, 1989; McWilliams and McKiernan, 1993; Parker et al., 1994; Stark et al., 1979).

In understanding the impact of domestic abuse upon women's health and well-being, it is important to take into account the social context in which this takes place. Abusive men often restrict and constrain women in ways which further damage their health. This may involve being prevented from accessing appropriate and timely health care such as antenatal care or emergency care to treat physical injuries inflicted by men (McFarlane et al., 1992; McWilliams and McKiernan, 1993). The outcomes of such restrictions are extremely difficult to determine, but are likely to be associated with long-term health problems, such as poor healing, scarring, future disability and chronic pain. The control inflicted by abusive men can also be damaging because it frequently prevents women from engaging in a range of everyday activities that may enhance their overall health or well-being. This may include, for example, restricted access to household finances and resources, as well as restrictions upon social activities and contact with family and friends. Not surprisingly many women respond to the abuse they are experiencing in ways which further damage their health, such as smoking, substance abuse, self-neglect and self-harm (see for example, Kelly, 1988; Stark et al., 1979; Webster et al., 1996; Williamson, 2000). For women who are pregnant, this is particularly harmful and is associated with both poorer maternal health status and poorer overall neonatal outcomes including low birth weight (Webster et al., 1996).

Thus developing an understanding of the impact of domestic abuse upon women's health requires careful analysis of the complex ways in which women's lives, and therefore their health, are constrained. Despite the range of evidence highlighting the health consequences of domestic abuse, there remains a need for further research to establish more detailed understandings, particularly the ways in which different experiences and 
types of abuse have a cumulative impact upon women's health.

\section{Domestic abuse and primary care}

Primary health care professionals are extremely well placed to provide care and support to women experiencing domestic abuse. Primary care is easily accessed by women and is often the first point of contact women seeking help about domestic abuse have with statutory agencies (Pahl, 1985). Largely as a consequence of their poor health status, abused women are frequent users of primary care services (Stanko et al., 1998), both during the period they are experiencing abuse, and in the long term when they are seeking help for chronic conditions that have been caused or exacerbated by abuse. Moreover the nature of primary care consultations, whether medical or nursing, offers women opportunities to present with one complaint, and then discuss another if the consultation is appropriately managed (Cowley, 1995). However a range of research evidence suggests that primary health care professionals often respond inappropriately and unsafely to women experiencing domestic abuse. Issues of concern include a poor knowledge base about domestic abuse and its impact upon health, a reluctance to address the issue of domestic abuse with clients considering it to be a private rather than a social issue, and little working knowledge concerning the provision of support and protection for women experiencing domestic abuse (Abbott and Williamson, 1999; Frost, 1997; McWilliams and McKiernan, 1993; Pahl, 1985; Peckover, 1998; Richardson and Feder, 1996). Research also suggests that additional difficulties are faced by certain groups of women, such as Black and Asian women and women with disabilities, due to inappropriate or inaccessible service provision (Mama, 1989; Rai and Thiara, 1997).

The difficulties women face in seeking help have led to considerable interest in domestic abuse and the role of health care professionals. For example, the increased awareness of the extent and impact of domestic abuse during pregnancy has highlighted the need to improve responses to women using maternity care services (Bewley et al., 1997; Mezey and Bewley, 1997; Royal College of Midwives, 1997). In particular, recommendations to introduce routine screening for domestic abuse through questioning, will impact upon the practice of community midwives and the management of pregnant women within primary care (Department of Health, 1998b, 2000). The recent nursing strategy states that '.. nurses, midwives and health visitors are often especially well placed to be able to identify and to help tackle the problem of domestic abuse' (Department of Health, 1999a, p. 61). Improving and developing good practice with individual clients is important for all primary health care professionals, and a number of practice guidelines and resources about domestic abuse produced by central government and many professional bodies are available (Bewley et al., 1997; British Medical Association, 1998; Community Practitioners and Health Visitors Association, 1998; Department of Health, 2000; Heath, 1992; Peckover, 2000; Royal College of Midwives, 1997). These recognize that good practice must incorporate safety and confidentiality, and that areas of practice which must improve include awareness, identification, responses, referral and support.

The development of good practice is underpinned by the need for improved education and training about domestic abuse for all primary health care professionals (Abbott and Williams, 1999; Frost, 1997; Kingston et al., 1995; Peckover, 1998). Local interagency domestic violence forums have an important role in providing and coordinating training (Hague et al., 1996). There are also a wide range of training materials available (for example, Hester et al., 1998; Peckover et al., 2001). Good practice would also be enhanced if domestic abuse was included in all pre- and postregistration, and post-qualification education and training programmes (Department of Health, 2000), although for this to be effective there is a need to ensure that students are conversant with feminist perspectives about the family and women's roles.

Primary care cuts across a number of organizational and professional boundaries, providing a challenging context for the development and introduction of good practice about domestic abuse. However, current developments within primary care, such as the establishment of Primary Care Trusts which have a population-based focus and are underpinned by health and social care partnership working, do provide an excellent opportunity to establish a local framework for the achievement 
of good practice which is evidence-based and reflects local needs and services. Clinical governance provides the means to develop and monitor good practice (Department of Health, 1998a). Supervision and support for staff is crucial to ensure safe and effective practice within primary care and this may be achieved through the framework of clinical supervision (Butterworth, 1992) or personal development plans (Department of Health, 1997b, 1998a). Ensuring the safety and support of primary health care team members can be addressed through improved team working, a process which may also ensure that practice responses are co-ordinated and coherent (see for example, Jenkins-Clarke et al., 1998; Long, 1996; Wiles and Robison, 1994; Williams and Sibbald, 1999). There is also an important role for domestic abuse to be addressed by new forms of primary care service delivery, such as NHS Direct and NHS Walk-in Centres.

Contemporary public policy on domestic abuse is underpinned by an emphasis upon interagency working (Home Office, 1999, 2000), and at a local level this can largely be achieved through domestic violence forums. Although previous work has highlighted the absence of health care sector representation within these bodies (Hague et al., 1996; Harwin et al., 1999), the current primary care reorganization, underpinned by partnership working and responding to local needs, provides the opportunity for Primary Care Trust representation and involvement with the local interagency domestic violence forum.

Recent significant changes in public health policy also provide opportunities for domestic abuse to be addressed (Department of Health, 1997a, 1999b). These changes include a recognition of the influence of the social context upon health, and of the continued existence of inequalities in health between social groups. This recognition has led to the development of a broad ranging policy to improve health. Of key significance within primary care is the Health Improvement Programme which entails the development of detailed plans about improving the health of the local population, and crucially reducing inequalities in health. This provides a framework for identifying, on a local basis, how domestic abuse impacts upon women's health, and for establishing targets to reduce this impact. This can be achieved through a range of policy and practice developments, appropriate to the local context, for example training and education programmes, screening, funding communitybased partnership support projects, etc.

The renewed public health perspective also recognizes the importance of interagency approaches to improving health and reducing health inequalities (Department of Health, 1997a, 1999b). There are a number of initiatives which are aimed at tackling crime reduction and social exclusion, such as Crime and Disorder partnerships, Health Action Zones and Sure Start programmes (Home Office, 1999) and these represent important opportunities for addressing domestic abuse.

\section{Increasing medicalization and professionalization?}

While the recognition of domestic violence as a health care issue is to be broadly welcomed, it is worth remaining cognisant of social science critiques which point to the increasing medicalization of life (Zola, 1972). Medicalization refers to the process whereby an issue such as domestic abuse, which was previously outside medical knowledge enters into medical discourse. In the context of domestic abuse the dangers of medicalization are evident. This may occur if domestic abuse becomes pathologized within medical knowledge, a process associated with understanding domestic abuse in terms of epidemiology and aetiology, rather than within a broader sociopolitical context. Similiarly medicalization also occurs when the practitioners approach focuses solely upon the presenting injury, symptom or sign, and fails to consider the broader context in which women experience domestic abuse. For example, the ways in which women's mental health, rather than domestic abuse, becomes the focus of medical attention has been highlighted in the findings of an earlier study undertaken in emergency care in North America (Stark et al., 1979) and more recently a key finding of work undertaken in this country (Williamson, 2000). The dangers of medicalization suggest that practice developments need to be introduced carefully, ensuring service effectiveness and sensitivity, while some initiatives such as the introduction of routine screening for 
domestic abuse will need to be implemented with caution (Department of Health, 2000).

There are also potential dangers if the issue of domestic abuse becomes not only medicalized, but also professionalized. While this may be an inevitable result of raised awareness, it does have a number of consequences which need to be addressed. The current renaissance of interest in the issue of domestic abuse has arisen because of the long-term work of voluntary sector organizations supporting women such as Women's Aid. These are underpinned by a feminist approach which informs their understanding of domestic abuse and ensures they engage in women-centred practice which aims to empower and support women throughout their struggles, regardless of their individual role, situation or behaviour. This involves challenging domestic abuse, as well as providing advocacy, practical and emotional support to women and their children. Given this substantial background and involvement it is therefore crucially important that future developments recognize and acknowledge the expertise of voluntary sector organizations, engaging in effective interagency working. Harwin et al. (1999) have raised concerns about the potential diluting of women-centred practice as the issue of domestic abuse becomes more mainstream. This may, however, represent a challenge to the professional base of organizations involved in primary care, who may be ill-equipped or unprepared to work in equal partnership with voluntary sector women's organizations, while their professional knowledge and power may act as barriers to developing women-centred practice (Hague et al., 1996; Harwin et al., 1999).

Raising the profile of domestic abuse within primary care policy and practice will also have a direct impact upon the volume of work undertaken by the voluntary sector. As more women seek help and are referred to voluntary sector services through primary care, this will increase the work of voluntary sector organizations such as Women's Aid who struggle for adequate funding and resources to ensure their services can be maintained. Therefore one of the challenges for strategic primary care development is to ensure that adequate resources are in place to maintain the services provided by the voluntary sector. This may be achieved through public health measures, such as the Health Improvement Programme.

\section{Conclusions}

Domestic abuse is a key public health issue which offers a number of challenges for primary care. Its importance relates not only to the burden it places upon women's health and welfare, but also because of the complex and long-term nature of the problem itself. Thus women experiencing domestic abuse are in frequent contact with primary care services, which, because of their preventive and longterm involvement, represent an important avenue for the provision of appropriate health care and support.

The recent academic and professional interest in domestic abuse as a health care issue has highlighted the need for practice to develop and improve for all professional groups working in primary care. Whilst this includes general practitioners, midwives, health visitors, practice nurses and other community specialist nurses, it also impacts upon those working in public health and health promotion, as well as other agencies such as social services, education and the voluntary sector. Current practice guidelines are based upon available research about responding to women experiencing domestic abuse. This is, however, limited in both scope and detail. For example much of the research evidence points to health visitors, with little mention of other groups such as practice or district nursing (Frost, 1997; Pahl, 1985; Peckover, 1998, 2000). Thus there is an urgent need for further research and development to ensure best practice.

Current organizational and philosophical developments within primary care provide a number of opportunities for addressing domestic abuse. These include primary care reorganization, strengthened public health, the emphasis upon interagency working and the development of new forms of service delivery. Achieving real changes in practice, however, represents a considerable challenge as it requires addressing individual professional practice, organizational and interorganizational issues. Domestic abuse is a complex issue and, in the context of primary care, will always be competing with more established clinical priorities. However, meeting the 
challenge in primary care is achievable, and one which not only represents an important contribution to interagency work on domestic abuse, but also has a direct impact upon the health and welfare of women.

\section{References}

Abbott, J. 1997: Injuries and illnesses of domestic violence. Annals of Emergency Medicine 29, 781-5.

Abbott, P. and Williamson, E. 1999: Women, health and domestic violence. Journal of Gender Studies 3, 83-102.

Abrahams, C. 1994: The hidden victims: children and domestic violence. London: $\mathrm{NCH}$ Action for Children.

Andrews, B. and Brown, G.W. 1988: Marital violence in the community. A biographical approach. British Journal of Psychiatry 153, 305-12.

Bewley, S., Friend, J. and Mezey, G. editors. 1997: Violence against women. London: Royal College of Obstetricians and Gynaecologists Press.

British Medical Association. 1998: Domestic violence: a health care issue. London: BMA.

Bullock, L. and McFarlane, J. 1989: The birth-weight/battering connection. American Journal of Nursing 89, 1153-5.

Butterworth, T. editor. 1992: Clinical supervision and mentorship in nursing. London: Chapman and Hall.

Community Practitioners and Health Visitors Association. 1998: Domestic violence. The role of the community nurse. London: CPHVA.

Council of Scientific Affairs. 1992: Violence against women. Relevance for medical practitioners. Journal of American Medical Association 267, 3184-9.

Cowley, S. 1995: In health visiting, a routine visit is one that has passed. Journal of Advanced Nursing 22, 276-84.

Department of Health. 1997a: On the state of the public health: the annual report of the Chief Medical Officer of the Department of Health for the year 1996. London: HMSO.

Department of Health. 1997b: The new NHS: modern, dependable. London: The Stationery Office.

Department of Health. 1998a: A first class service: quality in the new NHS. Leeds: Department of Health.

Department of Health. 1998b: Why mothers die: report on confidential enquiries into maternal deaths in the United Kingdom 1994-1996. London: The Stationery Office.

Department of Health. 1999a: Making a difference. London: Department of Health.

Department of Health. 1999b: Saving lives: our healthier nation. London: The Stationery Office.

Department of Health. 2000: Domestic violence. A resource manual for health care professionals. London: Department of Health.

Dobash, R.E. and Dobash, R.P. 1979: Violence against wives. New York: The Free Press.

Frost, M. 1997: Health visitors' perceptions of domestic violence. Health Visitor 70, 258-9.
Gielen, A.C., O’Campo, P.J., Faden, R.R., Kass, N.E. and Xue, X. 1994: Interpersonal conflict and physical violence during the childbearing year. Social Science and Medicine 39, 781-7.

Haber, J.D. 1985: Abused women and chronic pain. American Journal of Nursing 1010-2.

Hague, G., Malos, E. and Dear, W. 1996: Multi-agency work and domestic violence. A national study of inter-agency initiatives. Bristol: The Policy Press.

Harwin, N., Hague, G. and Malos, E. editors. 1999: The multiagency approach to domestic violence. New opportunities, old challenges? London: Whiting and Birch.

Heath, I. 1992: Domestic violence: the general practitioner's role. In Royal College of General Practitioners Members' Reference Book. London: Sabrecrown.

Helton, A.S., McFarlane, J. and Anderson, E.T. 1987: Battered and pregnant: a prevalence study. American Journal of Public Health 77, 1337-9.

Helton, A.S. and Snodgrass, F.G. 1987: Battering during pregnancy: intervention strategies. Birth 14, 142-7.

Hester, M., Pearson, C. and Harwin, N. 1998: Making an impact: children and domestic violence. A reader. London: Department of Health.

Hilberman, E. and Munson, K. 1977: Sixty battered women. Victimology: An International Journal 2, 460-70.

Home Office. 1999: Living without fear: An integrated approach to tackling violence against women. London: Home Office.

Home Office. 2000: Domestic violence: break the chain. Multiagency guidance for addressing domestic violence. London: Home Office.

Jaffe, P., Wolfe, D.A., Wilson, S. and Zak, L. 1986: Emotional and physical health problems of battered women. Canadian Journal of Psychiatry 31, 625-9.

Jenkins-Clarke, S., Carr-Hill, R. and Dixon, P. 1998: Teams and seams: skill mix in primary care. Journal of Advanced Nursing 28, 1120-6.

Kelly, L. 1988: Surviving sexual violence. Cambridge: Polity Press.

Kelly, L. 1994: The interconnectedness of domestic violence and child abuse: Challenges for research, policy and practice. In Mullender, A. and Morley, R., editors. Children living with domestic violence: putting men's abuse of women on the child care agenda. London: Whiting and Birch.

Kelly, L. and Radford, J. 1991: 'Nothing really happened': the invalidation of women's experience of sexual violence. Critical Social Policy 30, 39-53.

Kingston, P., Penhale, B. and Bennett, G. 1995: Is elder abuse on the curriculum? The relative contribution of child abuse, domestic violence and elder abuse in social work, nursing and medicine qualifying curricula. Health and Social Care in the Community, 3, 353-62.

Long, S. 1996: Primary health care team workshop: team members' perspectives. Journal of Advanced Nursing 23, 935-41.

Mama, A. 1989: The hidden struggle: statutory and voluntary sector responses to violence against Black women in the home. London: The London Race and Housing Research Unit.

McFarlane, J., Parker, B., Soeken, K. and Bullock, L. 1992: 
Assessing for abuse during pregnancy. Journal of American Medical Association, 267, 3176-8.

McGibbon, A., Cooper, L. and Kelly, L. 1989: What support? An exploratory study of council policy and practice, and local support services in the area of domestic violence within Hammersmith and Fulham. London: Hammersmith and Fulham Council Community Police Committee Domestic Violence Project. Polytechnic of North London: Child Abuse Studies Unit.

McWilliams, M. and McKiernan, J. 1993: Bringing it out in the open: women and domestic violence in Northern Ireland. Belfast: HMSO.

Mezey, G. and Bewley, S. 1997: Domestic violence and pregnancy. British Journal of Obstetrics and Gynaecology 104, 528-31.

Mirlees-Black, C. and Byron, C. 1999: Domestic violence: findings from the BCS self-completion questionnaire. Research Findings 86. London: Home Office Research Development and Statistics Directorate.

Mooney, J. 1993: The hidden figure: domestic violence in north London. London: Islington Council.

Muelleman, R.L., Lenaghan, P.A. and Pakieser, R.A. 1996: Battered women: injury locations and types. Annals of Emergency Medicine 28, 486-92.

Newberger, E.H., Barkan, S.E., Lieberman, E.S., McCormick, M.C., Yllo, K., Gary, L.T. and Schechter, S. 1992: Abuse of pregnant women and adverse birth outcome. Current knowledge and implications for practice. Journal of American Medical Association 267, 2370-2.

Pahl, J. 1982: Men who assault their wives: what can health visitors do to help? Health Visitor 55, 528-31.

Pahl, J. editor. 1985: Private violence and public policy: the needs of battered women and the response of the public services. London: Routledge.

Pahl, J. 1995: Health professionals and violence against women. In Kingston, P. and Penhale, B., editors. Family violence and the caring professions. Basingstoke: Macmillan Press Limited.

Parker, B., McFarlane, J. and Soeken, K. 1994: Abuse during pregnancy: effects on maternal complications and birth weight in adult and teenage women. Obstetrics and Gynaecology 84, 323-8.

Peckover, S. 1998: Domestic violence: on the health visiting agenda? Community Practitioner 71, 408-9.

Peckover, S. 2000: Domestic violence: a framework of good prac- tice. London: Community Practitioners and Health Visitors Association.

Peckover, S., Marshall, K. and Kendall, S. 2001: Understanding domestic violence. A training pack for community practitioners. London: Community Practitioners and Health Visitors Association.

Plichta, S. 1992: The effect of woman abuse on health care utilisation and health status: a literature review. Women's Health Issues 2, 154-63.

Rai, D.K. and Thiara, R.K. 1997: Re-defining spaces. The needs of Black women and children in refuge support services and Black workers in Women's Aid. Bristol: Women's Aid Federation of England.

Richardson, J. and Feder, G. 1996: Domestic violence: a hidden problem for general practice. British Journal of General Practice 46, 239-42.

Royal College of Midwives. 1997: Domestic abuse in pregnancy. Position Paper. No. 19. London: Royal College of Midwives.

Sampselle, C.M. editor. 1992: Violence against women: nursing research, education and practice issues. New York: Hemisphere Publishing Corporation.

Stanko, E., Crisp, D., Hale, C. and Lucraft, H. 1998: Counting the costs: estimating the impact of domestic violence in the London borough of Hackney. London: Children's Society and Hackney Safer Cities.

Stark, E., Flitcraft, A.H. and Frazier, W. 1979: Medicine and patriarchal violence: the social construction of a private event. International Journal of Health Services 9, 461-93.

Stark, E. and Flitcraft, A. 1996: Women at risk. Domestic violence and women's health. California: Sage Publications.

Webster, J., Chandler, J. and Battistutta, D. 1996: Pregnancy outcomes and health care use: Effects of abuse. American Journal of Obstetrics and Gynaecology 174, 760-7.

Wiles, R. and Robison, J. 1994: Teamwork in primary care: the views and experiences of nurses, midwives and health visitors. Journal of Advanced Nursing 20, 324-30.

Williams, A. and Sibbald, B. 1999: Changing roles and identities in primary care: exploring a culture of uncertainty. Journal of Advanced Nursing 29, 737-45.

Williamson, E. 2000: Domestic violence and health: the response of the medical profession. Bristol: The Policy Press.

Zola, I. 1972: Medicine as an institution of social control. The Sociological Review 20, 487-504. 